\title{
How low can you go?
}

Sarah Kilbourne, MD, ${ }^{\mathrm{a}}$ and Alexander Sasha Krupnick, MD ${ }^{\mathrm{b}}$

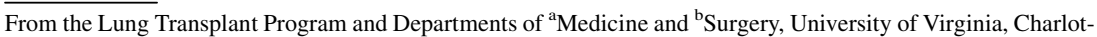
tesville, Va.

Disclosures: Authors have nothing to disclose with regard to commercial support.

Received for publication April 3, 2018; accepted for publication April 6, 2018; available ahead of print May 10, 2018.

Address for reprints: Sarah Kilbourne, MD, Department of Medicine, Division of Pulmonary and Critical Care, P.O. Box 800546, Charlottesville, VA 22908 (E-mail: skk2f@virginia.edu).

J Thorac Cardiovasc Surg 2018;156:892-3

$0022-5223 / \$ 36.00$

Copyright (C) 2018 Published by Elsevier Inc. on behalf of The American Association for Thoracic Surgery https://doi.org/10.1016/j.jtcvs.2018.04.023
}

Infection is a primary cause of early morbidity and mortality after lung transplantation; thus, routinely monitoring for immunoglobulin deficiency is common practice in the pretransplant evaluation. The role of immunoglobulin $\mathrm{G}(\mathrm{IgG})$ is often a focus in pre- and post-lung transplantation care, as it mediates serum defense. It has also been demonstrated that low posttransplant IgG levels are a risk factor for infectious complications. ${ }^{1,2}$ Interestingly, most of these infections occur across seromucous membranes (pulmonary, gastrointestinal, genitourinary, and sinus). Immunoglobulin A ( $\operatorname{IgA})$ is the most abundant antibody isotype, accounting for approximately $75 \%$ of the body's total immunoglobulin load, and is found in the mucous secretions of the respiratory, intestinal, and genitourinary tracts. ${ }^{3,4}$ Nevertheless, the correlation between IgA levels and infectious complications post-lung transplantation has never been assessed.

In this issue of the Journal, Murthy and colleagues from the Cleveland $\mathrm{Clinic}^{5}$ explored the association between IgA levels and seromucous infections early after lung transplantation. They further explored the association between pretransplant immunoglobulin levels and posttransplantation survival. Rather than stratifying patients by IgA levels outside of than the normal serum level range from 61 to $356 \mathrm{mg} / \mathrm{dL}, 3$ patients were stratified according to IgA into the lowest versus highest percentiles, as only $1.6 \%$ of patients had $\operatorname{IgA}$ levels below the lower limit of normal. They determined that values of $\operatorname{IgA}$ less than $200 \mathrm{mg} / \mathrm{dL}$ were associated with a nearly linear increase in risk of infection, whereas those above that level showed no relationship.

Through multivariate analysis of the seromucous infection, it was demonstrated that the association of IgA levels with infections increased in relationship to time after transplantation. It is particularly insightful to note that patients with a relative IgA deficiency (ie, low IgA levels, but not less than the lower limit of normal) and not just patients with an IgA less than the lower limit of normal were at an increased risk for seromucous infections. The authors then mirrored the same stratification with $\mathrm{IgG}$ levels by
Sarah Kilbourne, MD, and Alexander Sasha Krupnick, MD

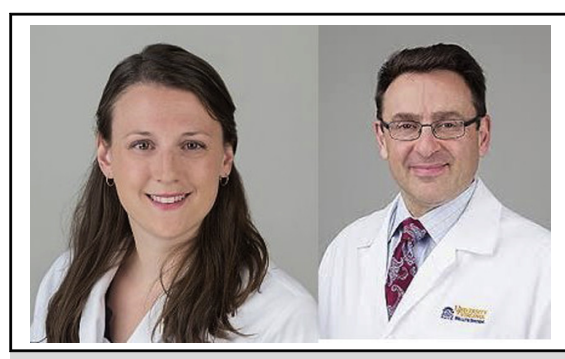

Central Message

Relatively low levels of IgA, detected pre-lung transplantation, are associated with increased seromucous infections, making the case for increased vigilance in monitoring for, and prophylaxis against, such infection.

See Article page 882 stratifying those with the lowest versus the highest 15 th percentile IgG levels. Although those patients in the highest 15th percentile experienced slightly more seromucous infections than those in the lowest 15th percentile, there were overlapping confidence limits. By multivariate analysis, unlike pretransplant IgA, there was no association between pretransplant IgG level and seromucous infections. Finally, lower pretransplant IgA level, but not lower IgG level, was a persistent, statistically significant risk factor for mortality throughout follow-up.

Such data provide critical, and previously unappreciated, guidance to the lung transplant community regarding risk stratification of recipients for infectious complications. Like any new discovery, this finding raises many new questions. Although this manuscript serves to highlight the importance of a robust seromucous defense mechanism in protecting against posttransplant infection, the question of the best therapy to treat this selective IgA deficiency is unresolved. Furthermore, patients undergo a battery of testing before transplant, including immunoglobulin serologies, but the challenge remains to sort out which facets of this broad testing are crucial pieces of evidence. Even the authors admit to not having paid attention to pretransplant IgA levels and their potential influence on posttransplant infections before this finding. ${ }^{5}$ At the very least, the data of Murthy and colleagues suggest that it may be wise to identify IgA-deficient patients before transplantation and maintain a high level of vigilance of monitoring for infection in this high-risk population. 


\section{References}

1. Goldfarb NS, Avery RK, Goormastic M, Mehta AC, Schilz R, Smedira N, et al. Hypogammaglobulinemia in lung transplant recipients. Transplantation. 2001; 71:242-6.

2. Yip NH, Lederer DJ, Kawut SM, Wilt JS, D’Ovidio F, Wang Y, et al. Immunoglobulin G levels before and after lung transplantation. Am J Respir Crit Care Med. 2006;173:917-21.

3. Abraham RS, Barnidge DR, Lanza IR. Assessment of proteins of the immune system. In: Rich RR, Fleisher TA, Shearer WT, et al., eds. Clinical

Immunology: Principles and Practice. 4th ed. Philadelphia, PA: Saunders; 2013:1145.

4. Delves PJ, Martin SJ, Burton DR, Roitt IM. Roitt's Essential Immunology. 12th ed. Chichester, West Sussex; Hoboken, NJ: Wiley-Blackwell; 2011. $50-1$.

5. Murthy SC, Avery RK, Budev M, Gupta S, Pettersson GB, Nowicki ER, et al. Low pretransplant IgA level is associated with early postlung transplant seromucous infection. J Thorac Cardiovasc Surg. 2018;156: 882-91.e8. 